\title{
Measuring what matters? Mapping higher education internationalization in the Asia-Pacific ${ }^{1}$
}

\author{
James H. Williams, Will Brehm \& Yuto Kitamura
}

\begin{abstract}
Internationalization of higher education has gained considerable momentum worldwide in recent years, and higher education in the Asia-Pacific region is arguably the world's most dynamic. Despite such dynamism in the region, no research to our knowledge has mapped the way in which internationalization is measured. Mapping the indicators of internationalization moves us a step closer in offering an explanation of the value of internationalization from the Asia-Pacific region. To develop this "map," this paper examines the use and misuse of indicators, setting up a discussion of our findings as to the current sources and uses of indicators in the Asia-Pacific and ways in which internationalization has been measured. The primary questions we tried to answer are: (1) What are the current available sources of data in the Asia-Pacific? And (2) How is internationalization measured in publicly available databases and academic materials in the AsiaPacific? The larger purpose of the paper is to develop a picture of what we know and do not know about the status of indicators of internationalization of higher education in the Asia-Pacific and their use.
\end{abstract}

\section{Introduction}

Internationalization of higher education has gained considerable momentum worldwide in recent years. It has become an integral part of the globalization process, in which higher education is no longer confined to the national context (Qiang, 2003), as well as a driver of academic capitalism where diverse private markets permeate the sector (Appe, 2020). Ennew and Greenaway (2012) note that the start of the twenty-first century has witnessed a remarkable expansion of international activity in scope and scale in higher education throughout the world. For many, these activities have become an important source of revenue for universities (particularly research universities) and in some cases investors (Bleak, 2017; Cantwell, 2015; Marginson \& Considine, 2000; Robertson \& Komljenovic, 2016). Such a transformation in the sector has resulted from "the development of advanced communication and technological services, increased international labor mobility, more emphasis on the market economy and the trade liberalization, focus on the knowledge society, increased levels of private investment and decreased public support for education and lifelong learning" (Knight, 2004, p. 7). It is now impossible, Van der Wende (2007) argues, for nations or higher education institutions to isolate themselves from the global effects of internationalization.

\footnotetext{
${ }^{1}$ This paper is based on a working paper prepared for the University of Tokyo and UNESCO Bangkok for the Indicators of Internationalization of Higher Education project, which was co-written with Chanphirun Sam and Risa Shibata (Williams, et al., 2017).
} 
In this context, higher education in the Asia-Pacific region is arguably the world's most dynamic. The UNESCO Institute for Statistics reports that 109 million students are enrolled in tertiary education in the Asia-Pacific, 53 percent of the world's total (UIS, 2016). Tertiary enrollment in the region has expanded rapidly, tripling since 2000. In 2013, 1.7 million higher education students in the Asia-Pacific studied abroad. Internationalization is taking place at multiple levels: the institution (and even program) level, the national level, regional and sub-regional levels, and globally. Like other regions, notably Europe and Latin America, much of the Asia-Pacific's internationalization work is regional in focus. Using Knight's (2012, p. 31) typology of approaches to internationalization, we have elsewhere (Williams, et al., 2017) compiled a list of functional networks and systems that aim to align higher education systems across Asia; organizations workings towards a shared structure across countries; and regional meetings aimed at building the political will to make domestic changes.

Despite the dynamism in the region, no research to our knowledge has mapped the way in which internationalization is measured. Mapping the indicators of internationalization moves us a step closer in offering an explanation of the value of internationalization from the Asia-Pacific region. To develop this "map," we articulated key issues and developed a working definition of internationalization of higher education, carried out a frequency analysis and discussion of the functions of internationalization currently available in the academic literature and in public indicator databases, and provided a summary characterization of the state of indicators of internationalization of higher education in the region.

The primary questions guiding our analysis are: (1) What are the current available sources of data in the Asia-Pacific? And (2) How is internationalization measured in publicly available databases and academic materials in the Asia-Pacific? The larger purpose of the paper is to develop a picture of what we know and do not know about the status of indicators of internationalization of higher education in the Asia-Pacific and their use.

The remainder of the paper is organized as followed. In the next section we detail and critique general definitions of internationalization used today, offering our own in conclusion. The next section details our method of a systemic review of literature and indicators, setting up a discussion of our findings as to the current sources and uses of indicators in the Asia-Pacific and ways in which internationalization has been measured. We end by discussing possible values implied in the various ways internationalization is measured.

\section{Definitions, Debates \& Concepts}

In this section, we review the contemporary debates over the meaning of internationalization. Based on this review, we detail our working definition at the end of the section, which will be used as the basis for the exploration of the various indicators used to measure internationalization in the Asia-Pacific.

Religion, colonialism, modernization, and global capitalism have been the main historical forces driving the internationalization of higher education in the Asia-Pacific. They have worked to various extents and in different places across time, occasionally overlapping and connecting with other international and domestic forces. Vietnamese Emperor Ly, for instance, established the 
Royal College, Quo Tu Giam (Temple of Literature) in 1076 modeled after Chinese institutions that were dedicated to the study of Confucianism (Welch, 2011, pp. 132-133). Hundreds of years later, Christian missionaries introduced liberal arts colleges in many parts of China (Chai, 2016). During $19^{\text {th }}$ Century European colonialism, the British Empire introduced its own version of higher education into India, Malaysia, and Singapore while the French shaped the systems in Vietnam and Cambodia (Altbach, 2004). Japan meanwhile borrowed foreign models of tertiary education (primarily that of the German research institutes) during the modernization reforms of the Meiji-era (1868-1912; Huang, 2007). Even the Soviet Union's system of "bureaucratic control and tight policy coordination" influenced many Central and Southeast Asian systems of higher education during and after the Cold War (Johnson, 2008, p. 162). The rise of global capitalism in the late $20^{\text {th }}$ Century has subsequently turned the "internationalization of curriculum'... [into] something of a slogan within modern corporatized educational systems" (Rizvi \& Lingard, 2010, p. 172). Today, it is rare for a university or a national ministry of education not to talk about internationalization in some way. Institutions across higher education systems may, however, have different or multiple purposes for internationalization. In neoliberal systems, international students are often conceptualized as providing a significant source of revenue to university budgets. Other systems, by contrast, may see internationalization as a means for public diplomacy - fostering international understanding or international development/cooperation - or as a way to build institutional or national capacity. These different conceptions of internationalization can co-exist simultaneously within the same institution. From this brief historical sketch, the Asia-Pacific region has experienced myriad forms of internationalization, each implying a certain value, purpose, or reason of/for the phenomenon. Today is no different.

The contemporary interest and use of the term "internationalization" have resulted in different meanings and interpretations (Knight, 1994, 2007; Qiang, 2003). What is internationalization and why is it pursued? At times, these questions have been conflated "such that a rationale for internationalization is often presented as its definition" (de Wit, 2008, p. 8). Is internationalization defined solely as student mobility, for instance, given the economic rational of increasing the number of fee-paying students or for other economic reasons? Or is internationalization more than mobility alone? Is internationalization the sum of various crossborder activities, such as student and faculty exchange, international collaborative research, establishment of branch campuses, etc. - in which tertiary institutions engage, or is it something inherent to the philosophy and day-to-day operation of the university? These questions have different answers depending on how one approaches the meaning of internationalization.

The most basic conceptualization of internationalization defines it through a set of activities. When students study abroad, the student's home or visiting university could decide such an activity signals its level of internationalization. The more students who go aboard, the more international a university becomes. Although there are clearly differences between student exchange programs - is traveling abroad over the summer holiday the same as studying for a whole year in a foreign country? Do some universities have more outbound and inbound students than others? Is learning a foreign language essential? - this set of activities is the sine qua non of internationalization. Among foreign students studying in OECD countries in 2008, China ranked first, followed by Japan and Korea ( $\mathrm{Ng}$, 2012). Several Asian universities have established degree programs offered in English to attract international students as well as English 
speaking native students interested in an international degree. A related set of activities concerns faculty exchange: visiting professors or scholar exchange programs, such as the Fulbright Scholar Program, and the like. Beyond academic mobility of students and professors, other activities include partnerships between universities, connections with governmental, nongovernmental, or business organizations, and collaborative research initiatives (Knight, 2004; 2007). The University of Nottingham Ningbo, for instance, was established in partnership with Zhejiang Wanli University in China (Huang, 2007). These activities signal in one way or another a university's level of internationalization, be it through the activities of exchanges, academic programs, or institutional collaborations.

Another way to define internationalization is through education delivery mechanisms that cross nation-state borders. When a university offers education beyond the borders of its home nationstate, internationalization, using this conceptualization, is said to occur. This can include the phenomenon of universities in one country opening a branch campus in another. Monash University in Australia, to take but one example, has opened a branch campus in Malaysia. Other international delivery mechanisms include franchising, such as Limkokwing University of Creative Technology, which although headquartered in Malaysia, has schools operating in eight other countries (Botswana, Cambodia, China, Indonesia, Lesotho, Sierra Leone, Swaziland and the United Kingdom), and using face-to-face and distance techniques of learning (e.g. Ennew \& Greenaway, 2012; Lo, 2016; Van der Wende, 2007). The rise of Massive Online Open Courses (MOOCS) can also be included in this definition of internationalization as a delivery mechanism that freely crosses boarders. Like the activities mentioned above, defining internationalization through delivery mechanisms results in a hodgepodge of possible meanings, which vary for each university (or organization, nation-state, and business).

There have been a few efforts to create a general definition of internationalization. The value of a general definition of internationalization is its ability to articulate the contours of the concept, which can be used to understand the phenomenon in practice across sites. This is different than conceptualizing internationalization as a set of activities or delivery mechanisms because such definitions limit possible meanings beyond the specific activities taking place. Important for this paper is that a general definition also allows researchers, university management, and policymakers to define indicators to measure the different aspects of internationalization rather than a wide assortment of activities and delivery mechanisms being carried out or used by universities. Of course, a general definition of internationalization should not be taken as static, since the contours of the concept change over time. Internationalization in the contemporary period, driven partly by profit seeking global enterprises, looks very different than historical internationalization of higher education in, for instance, Southeast Asia, which was driven partly by the movement of Buddhist monks and Confucian gentlemen.

Among the most cited definitions of internationalization of higher education are from Jane Knight. She describes internationalization as "the process of integrating an international, intercultural, or global dimension into the purpose, functions, or delivery of post-secondary education" (Knight, 2004, p. 11). In this definition, the term "functions" includes teaching, research, and service activities. The term "purpose" goes beyond the specific activities of students and professors to include an institutional perspective: what is the purpose of higher education and does it include an international dimension? Internationalization is conceived of (1) 
as between or among nation-states (the term "international"), (2) across cultures (the term "intercultural"), (3) and transnational in scope (the term "global"). Knight subsequently explored the global nature of higher education through an analysis of the trade rules of higher education services inside the World Trade Organization's General Agreement on Trade Services.

Knight's (2004) definition is broad enough to include the various activities and delivery mechanisms previously reviewed as well as institutional, national, cultural, and transnational dimensions. Additionally, the use of "post-secondary education" (rather than higher education institution, for instance) allows for the possibility to conceptualize internationalization not simply as a phenomenon inside universities but also something that can take place at the national system level - or even through regional and global networks, as we will argue below. It expands the level of internationalization, which may be mistakenly assumed to occur only at the university or individual program level.

Knight's definition was subsequently elaborated by de Wit, Hunter, Howard, and Egron-Polak (2015). They defined internationalization as "the intentional process of integrating an international, intercultural or global dimension into the purpose, functions and delivery or postsecondary education, in order to enhance the quality of education and research for all students and staff, and to make a meaningful contribution to society" (p. 283, emphasis removed). Compared to Knight's (2004) definition, de Wit and colleagues added that the process of internationalization was "intentional," meaning that it was premediated by some group of actors. Although this might be captured by Knight's use of "purpose," de Wit and colleagues make the point explicit. Moreover, they also include that internationalization of post-secondary education occurs "in order to enhance the quality of education and research for all students and staff and to make a meaningful contribution to society" (p. 283). Suggested in this phrase is the assumption that the rationale for internationalization is to improve the quality of higher education, and that post-secondary education is not simply a private individual good but rather a public good benefitting all of society.

Larsen (2016) critiques earlier definitions used by Knight (2004) and de Wit et al (2015), offering instead a conceptualization based on post-structuralism. She argues the definitions of Knight and de Wit and colleagues are implicitly normative, outlining what ought to be the meaning of internationalization. The definitions also assume that international is something external to the university, something that needs to be "brought in" (p. 4). Larsen specifically critiques the terms international, intercultural, and global, for assuming binary, static understandings of "home/abroad; local/global; and domestic/foreign" (p. 9).

Instead, she argues that internationalization should be understood through spatial theories (see for example Beech \& Larsen, 2014), which supposedly do not make normative assumptions. From this perspective, internationalization is not something external that needs to be brought in - not something that has one meaning which all universities should work towards — but is rather a social process through which actors within higher education interact to produce an international space. Internationalization is thus a phenomenon that emerges out of the global networks and flows (or students, faculty, and knowledge) that have come to mark the contemporary period of higher education. For Larsen, then, internationalization of higher education is "the expansion of the spatiality of the university beyond borders through mobilities 
of students, scholars, knowledge, programs, and providers" (p. 10). In this definition, Larsen privileges the ideas of spatiality and mobilities, seeing internationalization as socially constructed; as a process of becoming rather than a static thing. She also prefers the term "university" rather than post-secondary education and opts to include aspects that can be mobile (i.e., students, scholars, knowledge, programs, and providers) rather than Knight's focus on purpose, functions, and delivery, which are more abstract.

Considering the various general definitions of internationalization, we step into the debate by offering our own:

Internationalization of higher education is the intentional expansion of the spatiality of post-secondary education through cross-border mobilities and connections among institutions, students, scholars, knowledge, programs and delivery (systems and providers).

Like Larsen, we privilege the term spatiality to denote a post-structuralist stance by which internationalization is a socially constructed, not normative process. We see internationalization emerging out of the myriad processes and interactions which universities (and their students, faculty, and staff) - and national, regional and global actors alike - constantly undertake. Internationalization is hence constructed rather than achieved. This latter point is important because it re-focuses debates from what ought to be done to be considered "international" to one that explores how and to what effect current actions and interactions produce internationalization.

We diverge from Larsen in two ways. Like Knight (2004), we use the term "post-secondary education" rather than Larsen's use of "university" because we want to highlight (the social construction of) internationalization at levels above and below the university, including across national systems, within regional and global networks, but also at the program and individual student/faculty level. "Post-secondary education" is broad enough to capture these diverse possibilities, although in this paper we do not explore the individual level. Second, we use the term "cross border mobilities" rather than "beyond borders" as Larsen does because we want to recognize the importance of the (borders of the) nation-state but avoid methodological nationalism (Dale, 2005). Nation-states matter because universities must operate in and through diverse sets of domestic legal systems and structures. Moreover, international bodies working on higher education regionalization, such as UNESCO Bangkok, are made up of member nationstates. It is difficult to get away from nation-state borders. Nevertheless, we recognize that transnational forces operate beyond borders, such as for-profit global companies and the Internet. Cross border mobilities allow us to recognize the transnational (and potentially intra-national) forces while also acknowledging the power of the nation-state. We are neither bound nor beyond borders.

Some of the terms may require additional explanation. For us, "knowledge" includes research collaborations and ranking practices; "programs" primarily focus on education content (teaching, and curriculum) and "delivery" includes mechanisms and means, not only providers. This would include branch campuses, online learning, joint degree programs, etc. These terms capture, in our opinion, Knight's meaning of purpose, functions, and delivery while also capturing the 
specificity of Larsen's use of students, scholars, knowledge, programs, and providers. We do add the term "institutions" since they are left out of Larsen's list. We also add the term "connections among" since the activities and processes of internationalization sometimes result in entities staying put, not crossing borders at all.

Additionally, we use the word "intentional" similar to de Wit et al (2015) but do so with caution. We recognize that there is some level of intent when it comes to internationalization. It does not happen naturally; hence, our contention that studying indicators of internationalization is an entry point to understand the assumed purpose and value of internationalization itself. However, we would also suggest that intent is not always benign. It can be complex, political, and deeply contested. Whose intention is it to internationalize? For instance, policy makers may intend to internationalize not only because of its supposed effects on improvements in educational quality, but also because it may be a condition for funding from international financial institutions. Alternatively, intent may be constructed ideationally, through various summits where internationalization is discussed (Brehm, 2019), creating a discursive community where it becomes virtually impossible to imagine higher education without internationalization. Rizvi and Lingard (2011) call the ascendency of one social imaginary over others inside policymaking a "process of policy allocation" (p. 37). Determining intent in these situations is far more complex than assumed in some definitions. Studying indicators help us get around this issue.

\section{Methods}

In order to map and understand the current state of indicators of internationalization of higher education in the Asia-Pacific, we: (i) reviewed available sources (and uses) of data and indicators to understand the types of data currently available; (ii) developed a typology of functions of internationalization; and (iii) carried out a frequency analysis of those functions as seen in the academic and agency literatures and in online datasets.

In working to map indicators of internationalization of higher education in the Asia-Pacific, we carried out a library and Internet search, drew on the research team's own experience, and talked with experts in the region. Our examination of the situation in/about the Asia-Pacific suggests nine types of relevant data/indicators are available, summarized in Table 1. The results section discusses these nine types and sources of data.

Table 1. Types and sources of data/indicators in current use

1. International statistics on higher education

2. International statistics on internationalization of higher education

3. Government statistics

4. Institutional data

5. Regional data

6. University ranking/League tables

7. Institutional development focused indicators

8. Research data

9. Ad hoc 
Based on our general definition of internationalization, we developed a typology that allowed us to review both the literature on and indicators of internationalization. This typology included 10 categories and 34 sub-categories, which specifically focused on the various functions of internationalization (see Table 2). Our reporting here focuses primarily on the 10 categories. Available data were classified into subcategories where possible. Subcategories were also included as reminders of the meaning and breadth of the categories.

\section{Table 2. Detailed Classification of Internationalization Functions in Higher Education}

\section{Student mobility}

a. Outbound and inbound student mobility for degree programs (undergraduate, master, doctoral level)

b. In from Specific Regions/Countries \& Out to Specific Regions/Countries

c. Short-term vs Medium-term vs Degree-seeking

d. Undergraduate vs Graduate

e. Student exchange program

f. Academic partnership for home degree or joint degree

2. Faculty/Teaching staff mobility
a. Upgrading - degrees, short courses for professional development
b. Teaching in an overseas branch campus
c. Research
d. An individual short- or long-term faculty exchange program
e. Sabbaticals
f. Participation in overseas conferences
g. Part of academic partnership
h. Employment in foreign university

3. Research
a. Collaborative research for paper publications in international journals
b. Research collaboration for capacity development
c. Other research indicators (e.g., publications)

\section{Institutional linkages}
a. MOUs
b. Exchange agreements
c. Twinning/dual/joint degree programs
d. Institutional agreements/networks

5. International presence
a. Offices overseas
b. Branch campuses, foreign offshore campuses
c. Establishment of an educational provider abroad

6. Internationalization at home
a. Internationalization of the curriculum
b. International classroom
c. Online internationalization

7. Regional connectivity, harmonization, integration
a. Quality assurance (e.g., ASEAN University Network - Quality Assurance)
b. Qualifications frameworks, credit transfer
c. Other regionalization

\section{Ranking}

9. Planning for internationalization (e.g., national plan and/or policy; institutional planning; national visa consideration; legal foundations; etc.)
a. Plan to create an international school on campus
b. Plan for the establishment of full-fledge universities / world-class universities

10. Curriculum/educational program
a. Expanded roles of English in teaching and learning
b. Development of university curricula in which English is used as a medium of instruction 
c. Distance-learning program with other foreign universities /e-learning

d. Collaboration on twinning programs

e. A franchised and joint degree program with foreign universities (usually the prestigious ones)

f. Non-degree conferring programs and degree programs leading to degree of foreign universities

Using this typology, we then employed "a systematic literature review" (Tranfield, Denyer, \& Smart, 2003) approach to explore how internationalization of higher education is defined and interpreted in a sample of studies in the Asia-Pacific region as well as indicators appearing in databases available online and available for use.

The systematic review entailed extensive search of relevant literature (both academic and agency generated) on higher education internationalization in the Asia-Pacific. Terms were searched in combination with "higher education internationalization," including: cross-border education, regionalization, globalization, the Asia-Pacific, and Southeast Asia. Published scholarly journal articles and books as well as academic presentations and national/international reports were examined in the selection of literature. Several criteria were used to determine the priority of the literature to review. They included the relevance of the research to the review, quality of research in terms of its design and reporting, and the reviewer's judgement of the reliability and validity of the research findings. In total, the search resulted in 58 pieces of literature (both academic and national/international reports) being selected for further scrutiny. Since some sources were books with chapters on different countries in the Asia-Pacific region, we counted each chapter as a single source. At other times, academic presentations that were originally included were subsequently excluded during the analysis stage. We therefore limited our analysis to published academic studies or national/international reports, what we refer to as "literature" in the collective. The final sample size was 50 pieces of literature. The publications were then examined to decide which functions of internationalization in our typology were included, as well as a breakdown of geographic focus. Geographically, our sample covered 14 individual countries as well as documents that looked at Asia, Southeast Asia, or the Asia-Pacific (see Table 3).

\begin{tabular}{ll}
\hline Table 3: Geographic Focus of sources & \\
\hline Asia & 4 \\
Asia Pacific & 2 \\
Brunei Darussalam & 1 \\
Cambodia & 4 \\
China & 2 \\
India & 1 \\
Indonesia & 2 \\
Japan & 1 \\
Lao PDR & 2 \\
Malaysia & 5 \\
Myanmar & 1 \\
Philippines & 3 \\
Republic of Korea & 5 \\
Singapore & 6 \\
\hline
\end{tabular}




\begin{tabular}{lc}
\hline Southeast Asia & 7 \\
Thailand & 2 \\
Vietnam & 2 \\
\hline Total & $\mathbf{5 0}$ \\
\hline
\end{tabular}

We also reviewed both international and national indicators. International indicators, which covered the Asia-Pacific region, came from three sources: UNESCO Institute for Statistics, OECD, and Open Doors Report. We reviewed indicators coming from four country level data sources in the Asia-Pacific: Japan's Ministry of Education, Culture, Sports, Science and Technology (MEXT), Japan Student Services Organization (JASSO), Australia's Department of Education and Training, and India's Ministry of Human Resource Development. Since most countries in the Asia-Pacific had strict regulations for their data or did not conduct such research to begin with, not as much data could be found as initially anticipated.

After reviewing the national and international sources, we uncovered 54 indicators. Most indicators could be categorized under several sub-categories of our typology, since they included multiple aspects of student mobility. In these cases, we categorized the indicators twice, thus resulting in a final sample of 84 classified indicators.

Special attention was paid to the way each international institution defined key terms, such as higher education institutions and international students, as each organization had slightly different interpretations. Through the process, we discovered that there were some aspects of student mobility that were not fully covered under our original subcategories, including field of study and by gender.

The analysis of data was primarily accomplished by counting the prevalence of category and subcategories. Using a standard typology allowed us to compare the literature on internationalization (i.e., the "theory") with the indicators of internationalization available for use (i.e., the "practice"), as well as look at which aspects of internationalization were most common within each data set. Although the sample size is not exhaustive - and we could not review documents written in languages other than English, Japanese, or Khmer - our review provides general outlines of the landscape of higher education internationalization in the Asia-Pacific at one point in time before the COVID-19 pandemic.

\section{Findings}

This section reports findings of the primary focus of this research, a frequency analysis of the functions of internationalization as seen in the academic and agency literature. In the process, we carried out a synthesis of existing types and sources of data. Consideration of these multiple sources and types of data leads to several findings, stated as propositions:

Finding 1: There is no single source for a full range of data on internationalization in the AsiaPacific.

UIS and OECD and the ranking organizations provide the most comprehensive regularly collected and comparable data on internationalization of higher education, but the range of 
functions covered appears to be focused mostly on student mobility. This notion is examined precisely in more depth below. Additionally, UIS, OECD and most of the ranking organizations are headquartered outside the region and serve broader audiences.

Finding 2: Potentially rich data exist in the Asia-Pacific, but there is no system for making most of it available.

Following from the first point, there appears to be quite a lot of data collected, but they are often not comparable and not available for use. There is no "place" to put such data, and no system for standardizing them. As a result, a great deal of potentially useful information is inaccessible to larger audiences.

Finding 3: The patterns of (or possibilities for) use of most existing data remain unknown.

Without a closer look at the organizations generating and presumably utilizing indicators and data, it is difficult to know if and how indicators are being used. In moving toward regional system of indicators, it would be useful to survey how users use indicators and how they potentially might use them. Such a survey might include use of UIS, OECD and ranking data.

Finding 4: Rankings, arguably, are the among most influential of indicators of internationalization in use, yet their data are not publicly available.

Though evidence is anecdotal, experience in the Asia-Pacific suggests that rankings are taken quite seriously by some institutions and national governments. Not under government or international agency control, rankings instead call forth responses by institutions and governments seeking to improve their international standing. The influence of ranking privileges measures used to develop the composite scales on which rankings are calculated. Most of the indicators used in the rankings are not systematically collected by other institutions or available for broader public examination and use.

Because internationalization of higher education is a broad phenomenon with many different components and sub-components, we articulated a general definition that we then operationalized when reviewing academic literature and data made available by national and regional/global bodies. The findings draw on each of these sources.

Finding 5: Divergence between theory and practice.

The academic literature (i.e., the "theory" on internationalization) on higher education internationalization was found to capture the phenomenon's complexity, although favoring student mobility generally. After reviewing 50 pieces of literature across the Asia-Pacific region based on our 10-component typology of internationalization, we found that the main component favored in the literature was, by far, student mobility (88 percent of reviewed documents). The component that received the least attention in the literature was ranking (20 percent). The other eight components of internationalization were found to various extents in the literature, with curriculum/educational programs and faculty mobility accounting for the top spots after student mobility (see figure 1). 


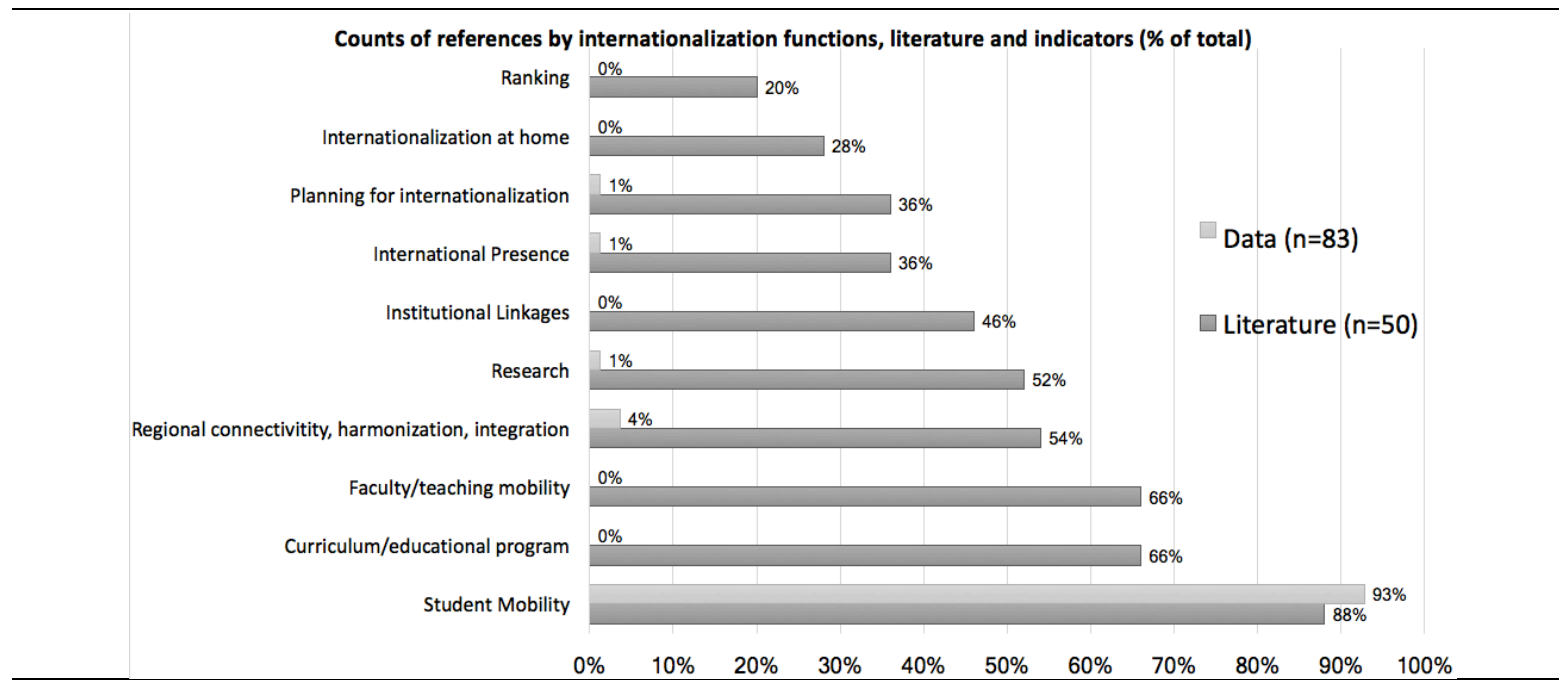

Figure 1: Counts by component of internationalization, literature and data (\% total)

Although we did not review all literature about internationalization, our sample does suggest that academics (and agencies) in the aggregate have looked at the phenomenon of internationalization in its complexity. Individual authors or agencies may focus on one component over another, but when viewed as a whole there is a diversity of writing on internationalization. The concept of internationalization within the academic and agency literature therefore, to a large extent, covers our general definition outlined earlier.

However, when we looked at data made available by national and regional/global bodies, a different story emerged. Whereas the academic and agency literature captured a range of meanings of internationalization, the available databases focus overwhelmingly on student mobility. Of 83 sources of data reviewed, 77 measured some part of student mobility (93 percent). Only six measured components of internationalization other than student mobility. These include three on regional connectivity and one each for research, planning, and international presence. (see figure 1).

Although we did not review all data collected across the Asia-Pacific (many countries, in fact, do not appear to measure anything related to internationalization), our sample suggests that the data collected overwhelmingly favor student mobility. This is different than the academic and agency literatures. Most of our general definition of internationalization remains un-measured in terms of current operationalization. Reasons why the literature diverges from the operational will be discussed in the next section. For now, this finding turned our attention to the data on student mobility: what were they measuring specifically and is it possible to compare student mobility across countries in the region? These are discussed in our next two findings.

\section{Finding 6: Indicators capture complexity of student mobility}

Since the overwhelming majority of data focused on student mobility, we decided to disaggregate the component by its sub-components. When we did this, we found that the 77 sources of data on student mobility touched upon each of our pre-determined sub-components (see figure 2). The largest sub-component were data that captured student mobility by country (35 percent). For instance, JASSO, specifically captured data on the number of international 
students by nationality. The second largest sub-component was student mobility by degree program. What type of degrees were students studying that went abroad? In our seventh finding, we will look at these types of data in more detail.

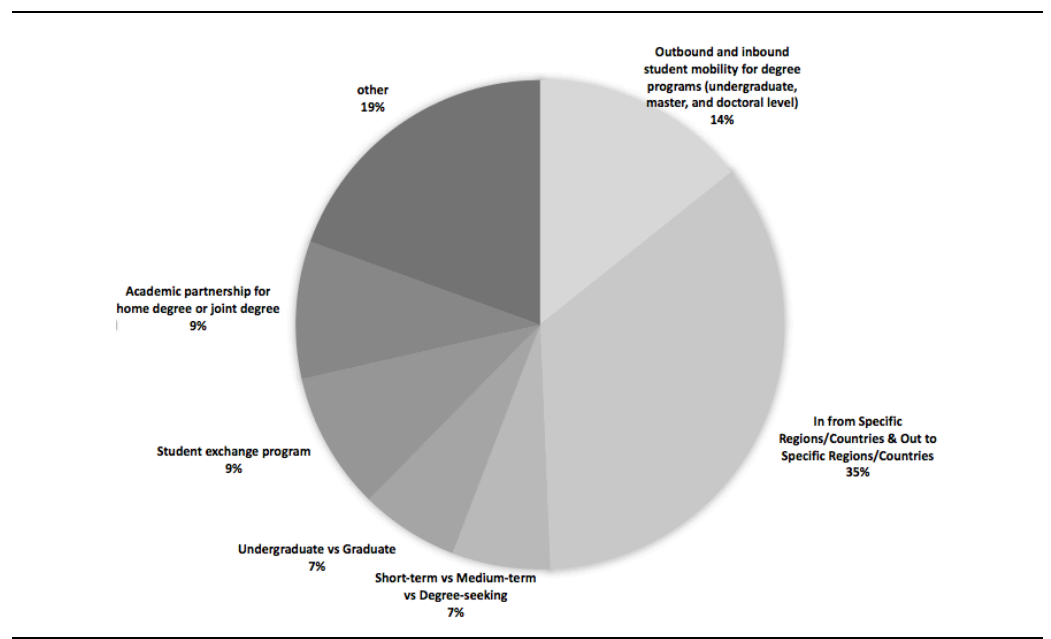

Figure 2: Breakdown of student mobility data, $N=77$

It was also found that 19 percent of data on student mobility did not fit neatly within our subcomponent typology. This suggests that our typology may not capture every aspect of internationalization as currently being measured by national and regional/global bodies. One type of data used by the Indian Government, JASSO, and the OECD, for example, focused on gender: how many female students studied abroad in which country, and for what degree? Although we could have categorized these in newly-created sub-components, we decided to mark them as "other" to highlight a gap in our typology. This shows the difficulty of moving from a general definition to operationalizing a typology. Despite these limitations, the general finding remains: student mobility is the primary focus of internationalization data, even as it often fails to capture the complexity of practice.

\section{Discussion \& Conclusion}

This paper provides a snapshot of indicators of internationalization of higher education in AsiaPacific. A fairly clear picture has emerged with a few key dimensions. By way of conclusion, we discuss some of these key dimensions that emerged from our analysis.

It is clear that most data are collected on the mobility function of internationalization, especially student mobility across universities. It is possible to develop a good idea of the macro flows of university students across borders. However, of the ten functions of internationalization of higher education identified earlier, there are virtually no data available beyond measures of mobility. And those measures generally lack qualitative detail or outcomes, focusing on numbers moving across borders, with less information about the length and nature of the programs of study, much less on outcomes or even participant satisfaction. Available indicators provide little insight into issues such as medium of instruction, funding sources, types of scholarships to support 
international mobility, etc. Vocational and non-university technical training is hardly discussed at all. Internationalization of higher education most certainly includes mobility of university students across national borders, but mobility alone does not make for comprehensive internationalization.

At the same time, the academic and agency literatures refer to a much broader range of indicators. An initial search for types and sources of currently available indicators suggests that substantial data are being collected and likely used in some way by a range of regional entities. These data are mostly not available, and mostly not comparable if available. The region lacks a system to store available data, and a mechanism for rendering them comparable. Indeed, this effort grew out of the lack of consensus about what should and feasibly could be measured and incorporated into a regional system of indicators.

Not surprisingly, almost all current indicators measure inputs and processes rather than outcomes. (Even so, indicators provide relatively little information about several key dimensions of our definition, particularly the connections among institutions, scholars, knowledge, programs and delivery and the mobilities of knowledge and delivery.) Recognizing that outcomes are more difficult to measure, there appears to be no consensus or discussion as yet even as to the appropriate outcomes to measure. To what extent should internationalization contribute, for example, to individuals' greater intercultural understanding, subject matter mastery, global or regional citizenship, greater individual self-efficacy, increased international competencies, language learning, etc.? As a result of the lack of measurement of outcomes, however, there is little systematic capacity to understand the effects of internationalization on individuals or institutions or at national, regional, and/or international levels. University rankings are, arguably and by default, one of the most influential types of statistic or indicator in common use, but there was little acknowledgement or discussion of them in the literature we reviewed.

A bigger question is why so much focus on simple measures of student mobility? Part of the explanation is surely the concreteness of the measures. Numbers of international students and numbers of students learning abroad do not require elaborate conceptualization and measurement, and the corresponding ease of collection. Complex questions such as improvements in global citizenship or changes in self-concept, intercultural learning capacities are difficult to conceptualize, much less measure on a systematic basis. Aside from research studies, no one in the global community appears to collect such information. But why not? For instance, in Southeast Asia, ASEAN seeks to establish regional integration and a corresponding regional identity across member states. Internationalization of higher education is promoted as a primary means for cultivating such identities. Yet such concepts do not appear to be systematically examined and reported.

Universities and governments take steps to internationalize for several reasons. Some countries use internationalization to develop their human capital in general and more specific technical fields of study. It is true that some universities in the region seek to "upgrade" their faculties by sending some faculty members abroad to study or carry out research or by welcoming international scholars to campus. Yet faculty exchange was much less reported than student mobility. 
Some governments may invite international students to their universities as part of their "knowledge diplomacy," international cooperation, or development assistance (Knight, 2018). Such government-sponsored international study aims at strengthening ties between sending and receiving countries. At the same time, it brings revenue to universities in the homeland. But the primary motivation may be political development of soft power.

Depending on the extent to which a country's universities are financially dependent on tuition fees, student mobility statistics likely track flows of such revenue. This would be of great interest to institutions and governments that rely heavily on tuition revenue from international students and may well explain much of the focus on student mobility. In this sense, the value of internationalization is to further academic capitalism (Slaughter \& Rhoades, 2004).

Internationalization of higher education takes place in the context of globalization, where universities serve students and the nation (and in some cases their owners), but compete in larger systems where rules of engagement are set at a global level operating within neoliberal political economic structures, as seen for example in rankings. The development of human capital; the strengthening of ties between countries, who may also be trading partners; the creation and maintenance of new streams of revenue to replace government support, all suggest a focus on student mobility, that and their concreteness and ease of collection. One can collect and report statistics on mobility without undertaking comprehensive internationalization, internationalization on the cheap.

The narrow focus on student mobility and the somewhat simplistic measurement of it limit the region's attention on other aspects of internationalization, acknowledged to be important by much of the literature reviewed. We know who travels and where, but we do not have a sense of what they learn, how, and to what effect. Since outcomes are rarely measured, we cannot know whether goals of internationalization are being achieved by mobile students. There are few measures of the scientific expertise picked up, the civic sensibilities of students, their regional identity, or of the culture and appreciation acquired. Given the high hopes of internationalization of higher education in pre-pandemic Asia-Pacific region, it seems a pity. What happens to internationalization of higher education as a result of coronavirus is to be determined.

Measurement of human activity always runs the risk of conflating what is important with what is measured, measurable, reported and used. Measurement allows comparison and tracking, but when the focus is too narrow, it short sights the development of alternative values, alternatives that may better capture the particular capacities, strengths, and needs of particular universities in specific contexts. Without more nuanced ways of thinking about the goals and functions of higher education, practice narrows to a least common denominator that really says very little. 


\section{References}

Altbach, P. G. (2004). The past and future of Asian universities. In P. G. Altbach \& T. Umakoshi (Eds.), Asian universities: Historical perspectives and contemporary challenges (pp. 132). Baltimore, MD: The John Hopkins University Press.

Appe, S. (2020). Internationalization in the context of academic capitalism. Research in Comparative and International Education, 15(1), 62-68.

Beech, J. and Larsen, M.A. (2014). Replacing old spatial empires of the mind: Rethinking space and place through network spatiality. European Education, 46(1), 75-94.

Bleak, J.L. (2017). When for-profit meets non-profit: educating through the market. London: Routledge.

Brehm, W. (2019). "Global Summitry and Clientelism in Cambodian Higher Education" in Jarvis, D.S.L. and Mok, J.K.H. (Eds.) Higher Education Governance in Asia: Policy Approaches, Innovations and Transitions (pp. 229-243). Singapore: Springer Nature.

Cantwell, B. (2015). Are International Students Cash Cows?: Examining the Relationship Between New International Undergraduate Enrollments and Institutional Revenue at Public Colleges and Universities in the US, Journal of International Students, 5(4), pp. 512-525.

Chai, W.Y. (2016). "Adapting the western model of liberal arts education in China: The Cases of Fudan University and Lingnan University.” In I. Jung, M. Nishimura, and T. Sasao (eds.) Liberal arts education and colleges in East Asia (pp. 75-86). Singapore: Springer.

Dale, R. (2005). Globalisation, Knowledge and Comparative Education, Comparative Education, 41(2), pp. 117-150.

de Wit, H. (2008). "The internationalization of higher education in a global context." In H. de Wit, P. Agarwal, M.E. Said, M.T. Sehoole, and M. Sirozi (eds.) The dynamics of international student circulation in a global context (pp. 1-14). Taipei: Sense.

de Wit, H., Hunter, F., Howard, L., \& Egron-Polak, E. (2015). Internationalisation of higher education study. Report for the European parliament's committee on culture and education: Brussels: European Union.

Ennew, C. T., \& Greenaway, D. (2012). Introduction and Overview. In C. T. Ennew \& D. Greenaway (Eds.), The globalization of higher education (pp. 1-16). New York, NY: Palgrave Macmillan.

Hazelkorn, E. (2011). Globalization and the Reputation Race in Rankings and the Reshaping of Higher Education: The Battle for the World. Palgrave MacMillan.

Hazelkorn, E. (2014). Rankings and the Striving for "World-Class Excellence": Rankings and Emerging Societies. In D. Araya and P. Marber (Eds.) Higher Education in the Global Age: Policy, Practice and Promise in Emerging Societies. Routledge.

Heinz-Dieter, M. (2017). The Limits of Measurement: Misplaced Precision, Phronesis, and Other Aristotelian Cautions for the Makers of PISA, APPR, Etc. Comparative Education, 53(1), $17-34$

Huang, F. (2007). Internationalization of Higher Education in the Developing and Emerging Countries: A Focus on Transnational Higher Education in Asia. Journal of Studies in International Education, 11(3-4), 421-432. doi: 10.1177/1028315307303919

International Association of Universities (IAU) (2017). Indicators and assessment. Accessed 30 June 2017 at http://www.iau-aiu.net/content/indicators-and-assessment 
Johnson, M. (2008). "The historical legacies of soviet higher education and the transformation of higher education systems in post-Soviet Russia and Eurasia." In The Worldwide transformation of higher education (pp. 159-176). Emerald.

Knight, J. (1994). Internationalization: Elements and Checkpoints. CBIE Research No. 7: ERIC.

Knight, J. (2004). Internationalization Remodeled: Definition, Approaches, and Rationales. Journal of Studies in International Education, 8(1), 5-31. doi: $10.1177 / 1028315303260832$

Knight, J. (2007). Internationalization: Concepts, Complexities and Challenges. In J. J. F. Forest \& P. G. Altbach (Eds.), International Handbook of Higher Education (pp. 207-227). Dordrecht: Springer Netherlands.

Knight, J. (2018). Knowledge Diplomacy: A bridge linking international higher education and research with international relations. Discussion paper published by the British Council. Accessed 10 October 2020 at https://www.britishcouncil.org/sites/default/files/kno.pdf

Larsen, M. A. (2016). Internationalization of Higher Education: An Analysis through Spatial, Network, and Mobilities Theories: Springer.

Lo, W. Y. W. (2016). Rethinking the notion of Hong Kong as a regional education hub: Toward a cosmopolitan approach to internationalization of higher education. Internationalization of Higher Education (pp. 63-77): Springer.

Marginson, S. \& Considine, M. (2000). The enterprise university: Power, governance and reinvention in Australia. Cambridge, UK: Cambridge University Press.

$\mathrm{Ng}$, S. W. (2012). Rethinking the mission of internationalization of higher education in the AsiaPacific region. Compare: A Journal of Comparative and International Education, 42(3), 439-459.

Qiang, Z. (2003). Internationalization of Higher Education: Towards a Conceptual Framework. Policy Futures in Education, 1(2), 248-270. doi: doi:10.2304/pfie.2003.1.2.5

Rizvi, F. and Lingard, B. (2010). Globalizing education policy. New York: Routledge.

Robertson, S.L. \& Komljenovic, J. (2016). Non-state actors, and the advance of frontier higher education markets in the global south. Oxford Review of Education, 42(5), pp. 594-611

Rowe, K. \& Lievesley, D. (2002). "Constructing and Using Educational Performance Indicators." Background paper to keynote address and workshops presented at the inaugural Asia-Pacific Educational Research Association (APERA) regional conference, ACER, Melbourne, April 16-19, 2002. Accessed 10 October 2020 at http://research.acer.edu.au/learning_processes/11

Slaughter, S. \& Rhoades, G. (2004). Academic Capitalism and the New Economy: Markets, State, and Higher Education. Baltimore, MD: Johns Hopkins University Press.

Tranfield, D. R., Denyer, D., \& Smart, P. (2003). Towards a methodology for developing evidence-informed management knowledge by means of systematic review. British journal of management, 14, 207-222.

Van der Wende, M. (2007). Internationalization of Higher Education in the OECD Countries: Challenges and Opportunities for the Coming Decade. Journal of Studies in International Education, 11(3-4), 274-289. doi: 10.1177/1028315307303543

Welch, A. (2011). Higher Education in Southeast Asia: Blurring borders, changing balance. New York: Routledge.

Williams, J. H., Brehm, W., Kitamura, Y., Sam, C. \& Shibata, R. (2017). Internationalization of Higher Education in the Asia-Pacific: Toward a Mapping of Indicators and their Utilization. Unpublished UNESCO Bangkok working paper. Bangkok: UNESCO. 